\title{
Some Thoughts on Physical Education Teaching in Colleges and Universities
}

\author{
Li Shirong \\ Yan'an University, Yan'an, Shaanxi, China, 716000,
}

Keywords: colleges and universities; physical education; thinking

Abstract: With the continuous progress of the times, the traditional physical education teaching mode can no longer conform to the development trend of the times. In teaching, teachers need continuous learning, change teaching ideas in time, actively innovate and reform college physical education teaching models. Only in this way we can follow up the pace of society, cultivate more innovative and highly qualified personnel. The article mainly discusses the importance and current situation of colleges and universities physical education, and summarizes some considerations of physical education in colleges and universities for reference.

\section{Introduction}

With the arrival of the new curriculum reform, college physical education has also put forward more stringent requirements for teachers. To become a good physical education teacher, we must not only improve the quality of students themselves, exercise the strong will of students, but also cultivate students' innovative ideas and innovative skills. This is the current standard of society for outstanding talents. [1]

\section{The Necessity of Physical Education}

\subsection{Cultivate students' hard-working spirit}

In many colleges and universities, many students hope to find a relaxed and earning job, lacking the hard-working spirit. Therefore, in the process of physical education teaching, teachers can use formation training, running training and throwing games to cultivate students' hard-working spirit. On the one hand, students are required to suffer from physical fatigue and muscle pain, and cultivate students' strong will and flexibility; On the other hand, strict compliance with disciplinary norms can improve students' discipline and control, allowing them to better control their mood and focus their attention. Let students know that there is no shortcut to success, they need to be down-to-earth pursuits and they will suffer tribulation and hardship in the search for success, but they must not withdraw in the face of difficulties, only bravely advance to succeed and experience this honor. [7] 


\subsection{Cultivate student sports habits}

Students are the hope of the country and need shoulder the responsibility of national construction, strengthen physical activity to make body strong, developing good fitness habits and a healthy lifestyle play a key role in the future development of the country. Therefore, through the exercise to make sports activities daily and institutionalized, thereby stimulating students' enthusiasm for participating in sports activities, from passive to active, develop good sports habits. After the students enter the society in the future, they can maximize the promotion and promotion of the development of mass sports, and allow more people to join physical exercise so that the masses can have a healthy body.

\section{The Status Quo of Colleges and Universities Physical Education}

\subsection{The concept of physical education is relatively backward}

At this stage, the majority of colleges and universities in physical education still use professional skills as the main training goal. In the classroom teaching, the teacher only teaches some simple sports skills, neglects the first goal of physical education in colleges and universities, and pays less attention to the students' comprehensive ability and physical fitness. In general, most teachers put too much emphasis on the student's grasp of the exercise method and did not reflect the actual exercise effect, this did not help to cultivate students' sportsmanship and improve their athletic skills. In addition, the most realistic problem faced in physical education in colleges and universities is the physical education exam, because sports scores do not affect the semester exams, so teachers do not pay enough attention to physical education exams, and even individual colleges and universities cancelled sports teaching and distributed physical education to other courses that required examinations. Physical education in colleges and universities has gradually become a nominal subject, which greatly reduces the overall ability of students' physical education. [6]

\subsection{The form of physical education is simple}

For a long time, most of the ordinary colleges and universities still use the traditional teaching mode of physical education curriculum subject. They pay too much attention to training students' professional skills, neglect the development needs of student diversity, and do not conduct in-depth teaching of students' true features and characteristics and advantages., to a certain extent it limits students' autonomy. Furthermore, the professional skills taught by the teachers are inconsistent with the actual life of the students, which increases the students' difficulty in practicing after school hours, making it difficult to increase the overall strength of the students' sports and constraining the development of physical education in colleges and universities.

\subsection{Lack of interaction between teachers and students}

In colleges and universities physical education, the teacher not only teach the students some simple and professional skills, but also improve the students' understanding and understanding of the sports spirit to a certain extent, strengthen the students' physical exercises, develop good behavior habits, and ensure the students' physical and mental health. However, in the daily teaching project, most teachers neglected the interaction with the students. They did not understand the interest of the students, and they used the one-size-fits-all education form, ignored the student's dominant position, did not put in place educational ideas in accordance with their aptitude. When formulating an assessment system, the teacher simply determines the mastery of the student's 
learning situation and does not communicate with the student to clearly identify the items to be paid attention to, and does not pay enough attention to the differences between individual students. To the extent that students are in conflict, this will not help the students' good habits.

\section{Some Thoughts on Physical Education Teaching in Colleges and Universities}

\subsection{Change the traditional sports teaching concept}

Teachers need to intensify the innovation of traditional sports teaching concepts, turn the teaching objectives originally intended to improve students' sports professional skills into teaching objectives that promote the physical and mental health development of students at the current stage. In general, it is necessary not only to enhance students' basic professional knowledge, but also to inspire students' enthusiasm for physical education in an all-round way. Under the premise of reasonable control of student characteristics and interests, implement a differential teaching model. In addition, the teacher should understand the necessity of physical education teaching in colleges and universities, and reasonably understand the transition of physical education in colleges and universities as the core of basic education. At the same time, in order to improve students' sports skills, they need also cultivate students' healthy and healthy sports habits. [2]

\subsection{Choose a diverse physical education model}

In physical education teaching, a reasonable choice of teaching model can improve the quality of teaching and the effect of teaching to a certain extent. From this, it needs to select the appropriate teaching mode in combination with the students' basic conditions. First of all, it is necessary to interact with the students frequently to understand the basic situation of the students and the progress of the study of the physical education courses so as to conduct targeted teaching. For example, teacher can disperse the existing group-based teaching and classify students according to their interests, hobbies, and characteristics. In addition, teacher teach some methods to allow students to practice independently, the teacher can provide guidance suggestions for each group at an appropriate time, with this it can stimulate the students' enthusiasm for learning and to stabilize the position of the students' education. [5] Second, we must formulate the teaching plan according to the students' physical qualities, meet the physical requirements of every student as much as possible, and teach the students some simple sports actions, so that students can relax under stressful conditions to cultivate students' healthy sports concepts. [3]

\subsection{Enhance communication with students}

In the early stage of diversified teaching for students, teachers should increase their interaction and interaction with students to fully understand the students' physical fitness, characteristics, advantages and operating interests, and lay a solid foundation for later teaching activities. At the same time, they can also use their communication methods to strengthen their affinity, attract a large number of students with their own personality charm, and stimulate students' enthusiasm for physical education. In addition, the use of communication means to clarify the sports assessment program, in colleges and universities physical education teaching, the training of outstanding sports talent is not the core content of this assessment process should not be too strict. In the process of formulating assessment rules, teachers should combine students' physical quality and physical advantage to perform comprehensive examinations and actively listen to students' suggestions. Based on this, it is necessary to add a comprehensive evaluation of college students' physical fitness, choose students self-assessment, mutual evaluation and teacher evaluation and other methods, but 
also refer to the college curriculum assessment model, according to the appropriate proportion of the physical education curriculum and test results to distinguish, In order to clarify the overall strength of students. [4] Through this method, students are allowed to participate in sports activities as much as possible, shortening the distance between excellent students and poor students, and using the golden mean to enhance the overall strength of college students.

\section{Analysis of College Physical Education Methods}

\subsection{Self-learning teaching mode}

In order to enhance students' ability to learn independently, the first thing the teacher needs to do is to inspire students' enthusiasm and enjoyment in physical education. In the traditional physical education teaching, teachers are usually following the sports materials in accordance with the rules to implement various teaching activities, so that students can have a targeted grasp of basic skills and repeated practice, but this kind of teaching model does not fully consider students' leading position in learning. Students in this passive learning state for a long time are vulnerable to conflict and have aversion to physical exercise. If teachers do not do supervision work properly, most students will have negative attitudes and will not develop the habit of self-learning. Therefore, with the continuous advancement of the new curriculum reform, teachers should change the traditional teaching model, focus on cultivating students' ability of independent learning, fully embody the main role of the students in teaching, consider the problems from the perspective of students, and fully explore the students' enthusiasm for learning, allows them to enter their own exploration of sports knowledge and practice of sports techniques to develop students' subjective initiative. In general, only by fully tapping students' interest and passion for physical education and stimulating students' enthusiasm and autonomy in sports training, can we fundamentally improve the quality and efficiency of physical education and enable students to better master physical knowledge and improve their quality literacy. [9]

\subsection{Cooperative learning teaching model}

The cooperative learning teaching model can better stimulate students' learning enthusiasm and enhance the quality of teaching by strengthening the interaction between teachers and students. For example, high school aerobics teaching belongs to a group activity program. It mainly focuses on sports training, it requires students to unite and strengthen communication, fully mobilizes students' enthusiasm and autonomy so that every student can show their own value in the group, and enhance students' self-confidence. While pursuing the purpose of teaching, students' team spirit and the fight will are cultivated. [8] In the cooperative learning process, the teacher's teaching form has changed significantly. The student becomes the master of the study, fully embodies the student's dominant position, and the strong sense of subjective inquiry makes students' interest in sports activities more and more profound. Let students with good physical fitness help students with poor physical fitness and make progress together. Students with slower acceptance ability can see the distance between themselves and other classmates, then they will do it harder. For class honor, other classmates are also making every effort to help the backward students, so that every student can work hard in unity, maximize the participation of students, improve the quality of teaching and teaching efficiency. For example, in the process of aerobics teaching, teachers should reflect their own value in the early stage of teaching. Students learn through watching and exercise reasonable control over the basic movements and training points of aerobics. In the middle and later stages, the teacher should guide the students correctly, highlight the subject position of the students, cultivate the students' independent learning ability and teamwork innovation ability, and prepare more aerobics 
movements that meet the student's characteristic requirements so that each student can participate, and students' subjective initiative is fully displayed, making physical education classroom become a space for students to learn and exercise independently.

\subsection{Adopt innovative teaching mode}

Modern educational thinking refers to the teacher should create a healthy, relaxed and warm teaching atmosphere for the students, so that students can maintain their physical and mental pleasure in sports teaching, so as to gain more sports knowledge and sports skills to improve the professional quality. In the physical education of colleges and universities, if we want to improve the teaching quality and teaching effectiveness of teachers, we must fully tap students' interest and enthusiasm for learning so that students can enjoy the joy brought by sports activities. In the classroom, students are allowed to master basic movements and technical essentials so that students can really feel the meaning of sports. After the students complete the exercise task and display it, they will be recognized by teachers and classmates, then students will get satisfied in the heart, and finally fell in love with sports teaching and fell in love with sports. In combination with aerobics teaching, when students fully understand the basic aerobics movements, the teacher should appropriately guide students to switch from passive learning to active learning, explore and innovate in aerobics action combinations, enable students to recognize the unique charm of sports, so as to better train students' application skills. In the innovative teaching process, teachers can instruct the students to integrate a large number of sports elements into the total rehearsal of aerobics. For example, many students like Latin dance and hip-hop and broaden their skills. The teacher should evaluate the students' ability and progress in a timely manner, encourage and praise them more, and discover the unique bright spots of each student, so that every student can confidently participate in physical exercise. [10]

\section{Methods of Cultivate Students' Sports Awareness}

\subsection{Give full play to the value of physical education}

In physical education, physical class is an important part of it and it is the core content of school physical education. Therefore, in the process of physical education teaching, college teachers should fully demonstrate their own value and fully display students' subjective initiative, deepen their love of sports to cultivate the spirit of sports. Teachers need to intensify ideological education for students, and often teach students the importance of national fitness activities for sports and physical \& mental health. Moreover, physical education teachers should improve their own qualities and set an example for students.

\subsection{Organize diverse sports competitions}

In sports competitions, the patriotic spirit that athletes win glory for the country infects the entire nation, embodying education and encouragement. In social sports, the collective spirit of solidarity and mutual assistance is fully displayed. Natural sport competitions are not only between traditional athletic events but also among various classes. In order to realize the goals of full-time action, participation of all, and inspire students' interest in sports, they can choose different ways. For example, colleges and universities should pay attention to sports competition and basketball games, and organize events such as tug-of-war and fun sports games during their spare time. 


\section{Conclusion}

In summary, with the continuous reform of education, in the process of physical education in colleges and universities, teachers should not only guide students to understand the professional knowledge and professional skills of various types of sports competitions, but also tap students' innovative thinking in the teaching process. Focus on cultivating students' ability to encounter problems, comprehend problems, and handle problems. In physical education teaching, teachers should fully reflect the students' leading position, fully mobilize the students' enthusiasm and initiative, and maximize the quality of physical education and teaching efficiency.

\section{References}

[1] Zherui Zhang. Some Thoughts on Physical Education Teaching in Colleges and Universities[J], Academic Weekly, 2016, (14):126-127.

[2] Chao Zhang. Some Thoughts on Physical Education in Senior High School under the New Situation[J], Academic Weekly, 2016, (33):53-54.

[3] Bin Wu. Some Thoughts on Improving the Efficiency of High School Physical Education Teaching[J], New Course Guide, 2015, (7):83-84.

[4] He Zheng, Some Thoughts on Colleges and Universities Sports Teaching [J]. SME Management and Technology, 2016, (1):188-189.

[5] Lemen Chao, Talking About the Thinking of Physical Education In High School [J]. Education Science, 2016, (11):288-289.

[6] Sheng Zhou, Current Problems and Countermeasures In High School PE Teaching[J]. Education Modernization, 2017, (7):85-86.

[7] Jinge Lu, Some Thoughts on Students' Study Method in Physical Education Teaching[J]. Section Guidance, 2016, (1): $115-116$.

[8] Yin Liu, Reflections on the Application of Happy Sports in Middle School PE Teaching[J]. Inner Mongolia Education, 2016, (30):81-82.

[9] Fei Xue, Reflections on Physical Education in Senior High School[J]. Education, 2015, (29):208-210.

[10] Faliang Yu, Reflections on the Current High School Physical Education Curriculum Reform[J]. Shanxi Youth, 2015, (19):25-26

Li Shirong, male, Wu Qi, Shaanxi, November 1970, Yan'an University, Master's degree supervisor, Associate Professor, College of physical Education, Yan'an University, Yan'an University 